\title{
KARAKTERISASI KURVA HORIZONTAL-TO-VERTICAL SPECTRAL RATIO: KAJIAN LITERATUR DAN PERMODELAN
}

\begin{abstract}
Oleh:
Sungkono ${ }^{1)}$, B.J. Santosa ${ }^{2)}$

ABSTRAK: Metode Horizontal-to-Vertical Spectral Ratio (HVSR) dapat digunakan untuk mikrozonasi kerusakan bangunan akibat gempabumi yang disebabkan efek lokal (geologi setempat). Untuk mengetahui karakter geologi yang dapat merusak bangunan akibat gempabumi, maka perlu dilakukan kajian literatur dan karakterisasi HVSR. Hasilnya ialah, kerusakan bangunan akibat gempabumi terjadi pada parameter HVSR amplifikasi tinggi dan frekuensi rendah. Amplifikasi berbanding lurus dengan kontras impedansi (kecepatan gelombang geser (Vs) dikalikan densitas) antara sedimen dan bedrock, kecepatan gelombang primer ( $\mathrm{Vp}$ ) dan faktor quasi gelombang geser (Qs). Sedangkan frekuensi natural berbanding lurus dengan Vs rata-rata dan berbanding terbalik dengan ketebalan sedimen permukaan. Dengan demikian, daerah rawan kerusakan bangunan akibat gempabumi terjadi pada daerah sedimen lapuk (misal: pasir, pasir lanauan, gambut) yang yang tebal dan atau sedimen lapuk yang terdapat diatas batuan yang keras.
\end{abstract}

Kata Kunci: Permodelan, karakterisasi, HVSR

\section{PENDAHULUAN}

Nakamura (1989) mengusulkan metode HVSR untuk mengestimasi frekuensi natural dan amplifikasi geologi setempat dari data microtremor. Perkembangan selanjutnya, metode ini mampu untuk mengestimasi indeks kerentanan tanah (Nakamura, 1997), indeks kerentanan bangunan (Sato et al., 2008; Triwulan et al., 2010) dan interaksi antara tanah dan bangunan (Gallipoli et al., 2004; Triwulan et al., 2010). Metode ini berhasil untuk melokalisir daerah yang rawan kerusakan bangunan akibat efek lokal (Panou et al., 2005), likuifaksi (Huang dan Tseng, 2002), interaksi antara bangunan dan tanah (Mucciarelli et al., 2004), dan kekuatan bangunan (Nakamura et al., 2000). Metode HVSR ini merupakan metode yang efektif, murah, dan ramah lingkungan yang dapat digunakan pada wilayah permukiman. Metode HVSR biasanya digunakan pada seismic pasif (microtremor) tiga komponen.

Parameter penting yang dihasilkan dari metode HVSR ialah frekuensi natural dan amplifikasi. HVSR yang terukur pada tanah yang bertujuan untuk karakterisasi geologi setempat, frekuensi natural dan amplifikasi berkaitan dengan parameter fisik bawah permukaan (Herak, 2008). Sedangkan HVSR yang terukur pada bangunan berkaitan dengan kekuatan bangunan (Nakamura et al., 2000) dan keseimbangan bangunan (Gosar et al., 2010).

Berkaitan dengan HVSR untuk karakterisasi geologi lokal, perlu diketahui parameter-parameter bawah permukaan yang mempengaruhi frekuensi natural dan

${ }^{1,2)}$ Jurusan Fisika, FMIPA, ITS, Keputih 60111 Surabaya Indonesia

(Korespondensi Penulis:hening_1@physics.its.ac.id)

Created with 
amplifikasi. Hal ini mempunyai tiga tujuan. Pertama, interpretasi microzonasi dengan HVSR dapat dilakukan secara tepat. Kedua, mengetahui penyebab kerusakan akibat gempa dapat diketahui secara pasti. Ketiga, sebagai pertimbangan dalam mengekstraksi parameter bawah permukaan dengan kurav HVSR.

Agar dapat mengetahui parameter yang berpengaruh pada frekuensi natural dan amplifikasi, perlu dilakukan karakterisasi kurva HVSR melalui pemodelan kedepan. Dalam karakterisasi HVSR, perlu dikaetahui model gelombang yang terkandung dalam HVSR terlebih dulu. Gelombang yang terkandung dalam HVSR masih terdapat perbedaan (Dal Moro, 2010a; 2010b). Nakamura (2000) berpendapat bahwa HVSR merupakan gelombang badan, dalam hal ini gelombang SH, sedangkan Bonnefoy- Clauded et al. (2006a) menunjukkan bahwa HVSR terpengaruh gelombang permukaan, dalam hal ini gelombang Love dan Rayleigh. Oleh karena itulah, pada paper ini akan dipaparkan gelombang yang terkandung pada kurva HVSR dan karakteristik kurva HVSR berdasarkan permodelan kedepan dan kajian pustaka.

\section{Gelombang pada HVSR Microtremor}

Nakamura (1989) mengembangkan konsep HVSR dengan asumsi microtremor didominasi oleh gelombang geser dan mengabaikan gelombang permukaan (gelombang Rayleigh dan Love). HVSR ini dianggap sama dengan fungsi transfer antara getaran gelombang pada sedimen dan bedrock. Artinya, amplituduh dan frekuensi peak HVSR merepresentasikan amplifikasi dan frekuensi setempat.

Menurut Bonnefoy-Cludet et al. (2006b) bertasarkan tinjauan pustaka, gelombang microtremor tersusun atas gelombang Rayleigh dan Love dengan proporsi tertentu, sebagaimana pada tabel 1. Sebab, microtremor bersumber pada gelombang laut, angin, getaran akibat aktifitas gunung, dan getaran akibat aktifitas manusia (Bonnefoy-Caludet et al., 2006b). Konno dan Ohmachi (1998) memaparkan bahwa walaupun microtremor didominasi oleh gelombang permukaan (Rayleigh dan Love), namun HVSR yang dikenalkan oleh Nakamura (1989) merepresentasikan karakteristik setempat.

Tabel 1 Proporsi kandungan gelombang Love dan gelombang Rayleigh pada gelombang microtremor (Bonfoy-Cludet et al., 2006b)

\begin{tabular}{|l|l|l|l|l|}
\hline \multicolumn{1}{|c|}{ Peneliti } & \multicolumn{1}{c|}{$\begin{array}{c}\text { Range } \\
\text { Frequensi }\end{array}$} & \multicolumn{2}{c|}{ Proporsi Gelombang } & \multirow{2}{*}{ Tempat } \\
\cline { 3 - 5 } & Rayleigh & Love & \\
\hline Chouet et al. (1998) & $>2 \mathrm{~Hz}$ & $23 \%$ & $77 \%$ & Pegunungan \\
\hline Yamamoto (2000) & $3-8 \mathrm{~Hz}$ & $<50 \%$ & $>50 \%$ & $\begin{array}{l}\text { Sedimen (kedalaman } \\
<100 \mathrm{~m})\end{array}$ \\
\hline $\begin{array}{l}\text { Arai dan Tokimatsu } \\
(1998)\end{array}$ & $1-12 \mathrm{~Hz}$ & $40 \%$ & $60 \%$ & $\begin{array}{l}\text { Sedimen (kedalaman } \\
<100 \mathrm{~m})\end{array}$ \\
\hline Cornou (2002) & $0.1-1 \mathrm{~Hz}$ & $50 \%$ & $50 \%$ & $\begin{array}{l}\text { Sedimen (kedalaman } \\
\sim 500 \mathrm{~m})\end{array}$ \\
\hline Okada (2003) & $0.4-1$ & $<50 \%$ & $>50 \%$ & $\begin{array}{l}\text { Sedimen (kedalaman } ~ \\
\mathrm{~m})\end{array}$ \\
\hline K $\square$ hler et al. & $\begin{array}{l}0.5-1.5 \\
\mathrm{~Hz}\end{array}$ & $10-35 \%$ & $65-90 \%$ & $\begin{array}{l}\text { Sedimen (kedalaman } \\
\sim 200 \mathrm{~m})\end{array}$ \\
\hline
\end{tabular}


Selanjutnya, Beberapa peneliti (Arai dan Tokimatsu,1998; 2000; Castellaro dan Mulargia, 2009) memaparkah bahwa kurva HVSR merupakan kontribusi gelombang permukaan. Sedangkan, Bonnefoy-Claudet et al. (2006a) berpendapat bahwa kurva HVSR ialah gabungan antara gelombang permukaan dan frekuensi resonansi gelombang S. Rosenblad dan Goetz (2010) menunjukkan bahwa frekuensi natural yang diestimasi dari HVSR gelombang S dan gelombang Rayleigh mempunyai nilai yang hampir sama, tetapi amplifikasinya berbeda jauh.

Meskipun beberapa peneliti berpendapat bahwa kurva HVSR tersebut terdapat sumbangsih pada gelombang permukaan, terutama pada frekuensi fundamental, HVSR yang berbasis gelombang badan (Herak, 2008) merupakan pendekatan yang lebih baik dari pada pendekatan dengan gelombang permukaan beberapa mode (Albarello dan Lunedei, 2010; Dal Moro, 2010c).

Dal Moro (2010c) memaparkan bahwa dengan pendekatan gelombang badan (Herak, 2008), frekuensi dasar lebih tepat daripada gelombang permukaan. Dal Moro (2010a; 2010c) juga menjelaskan bahwa pada frekuensi tinggi, kurva observasi HVSR terkadang terdapat puncak (gambar 1). Hal ini menunjukkan bahwa kurva HVSR observasi pada frekuensi tinggi terdapat sumbangsih gelombang permukaan. Selain itu, pada frekuensi rendah, kondisi angin dan cuaca dapat mempengaruhi HVSR (Ali et al., 2010) dan noise lingkungan juga turut berperan dalam mempengaruhi puncak frekuensi rendah (Parolai et al., 2004), sebagaimana gambar 1. Ini didukung oleh Oliviera et al. (2006), yang mengatakan bahwa amplifikasi atau puncak kurva HVSR dapat lebih dari satu, dan amplifikasi pada frekuensi tinggi patut untuk dipertimbangkan.

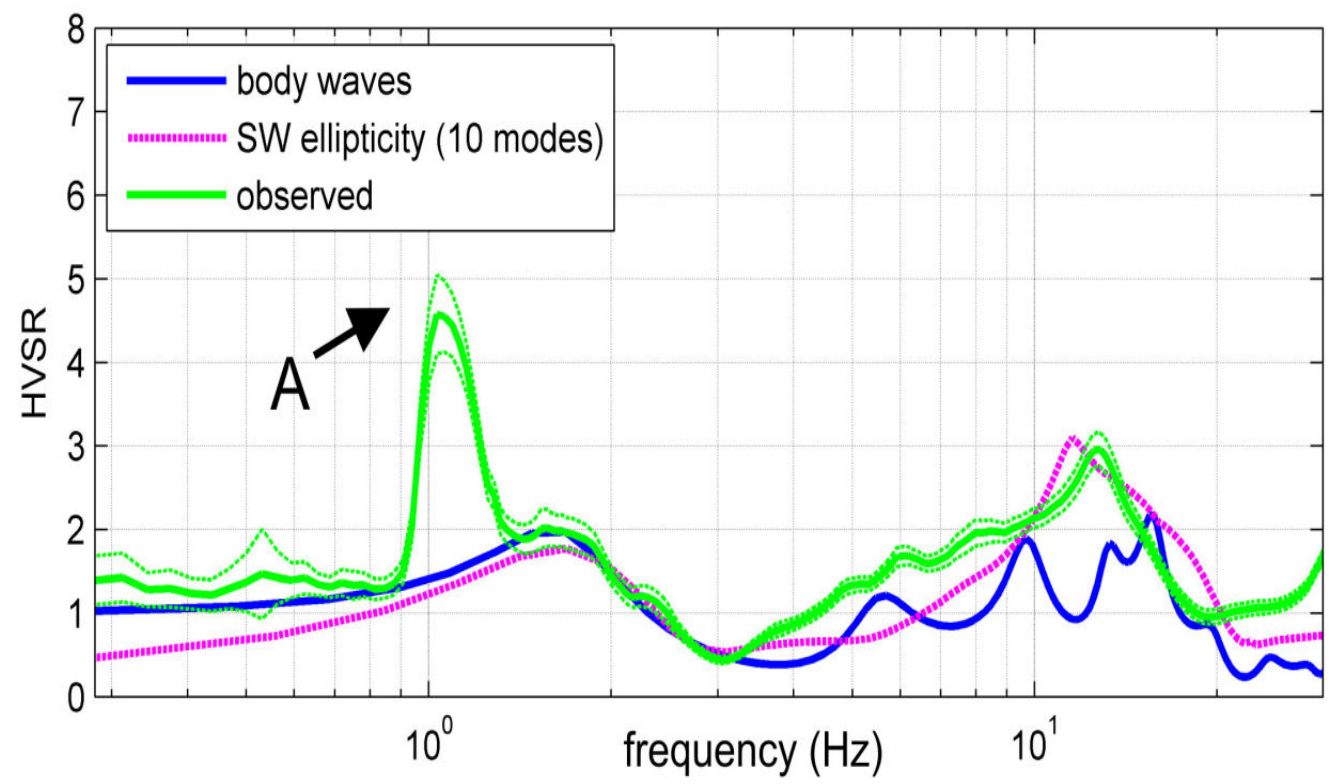

Gambar 1. Perbandingan kurva HVSR. HVSR pengukuran, permodelan dengan basis gelombang badan dan gelombang permukaan mode dasar sampai mode ke-9 (Dal Moro, 2010a). 
Untuk mengetahui pendekatan yang tepat (antara gelombang badan dan gelombang permukaan) pada kurva HVSR, perlu dilakukan simulasi numerik dengan menggunakan software ModelHVSR (Herak, 2008) dan microtrem (Lunedei dan Albarello, 2009). ModelHVSR berbasis gelombang badan, sedangkan microtrem berbasis multi mode gelombang permukaan (Rayleigh dan Love) dan keduanya berbasis viskoelastis. Simulasi ini dilakukan dengan data input pada tabel 1. Hasil simulasi ini, seperti pada gambar 2. Berdasarkan gambar ini, diketahui frekuensi natural dan amplifikasi gelombang badan lebih kecil jika dibandingkan dengan gelombang permukaan.

Selanjutnya, dilakukan perhitungan frekuensi (f) berdasarkan Nakamura (2000) serta Rošer dan Gosar (2010), sebagaimana persamaan 1. Hasil perhitungan frekuensi natural dengan persamaan ini dihasilkan $5.14 \mathrm{~Hz}$, sedangkan dari HVSR gelombang badan frekuensi dihasilkan $5 \mathrm{~Hz}$ dan frekuensi natural dari HVSR gelombang permukaan (15 mode) $6.4 \mathrm{~Hz}$. Dengan demikian, dapat diketahui bahwa pendekatan gelombang badan lebih baik dari pada gelombang permukaan.

Tabel 2. Parameter model perbandingan kurva HVSR berbasis gelombang badan dan gelombang permukaan

\begin{tabular}{|c|c|c|c|c|c|}
\hline $\mathrm{Vp}(\mathrm{m} / \mathrm{s})$ & $\mathrm{Vs}(\mathrm{m} / \mathrm{s})$ & $\mathrm{H}(\mathrm{m})$ & $\rho\left(\mathrm{gr} / \mathrm{cm}^{3}\right)$ & $\mathrm{Qp}$ & Qs \\
\hline 200 & 100 & 2 & 1.8 & 20 & 10 \\
\hline 400 & 200 & 5 & 1.8 & 40 & 20 \\
\hline 800 & 400 & 10 & 1.8 & 60 & 30 \\
\hline 1400 & 700 & $\infty$ & 1.8 & 180 & 90 \\
\hline
\end{tabular}

$$
f=\frac{\overline{V_{S}}}{4 h}
$$

Dengan $\bar{V}_{s}$ dan h secara berturut-turut ialah rata-rata kecepatan gelombang geser dan kedalaman bedrock.

Menurut Nakamura (2008), pada frekuensi natural, energi gelombang Rayleigh mendekati nol, sedangkan pada frekuensi yang lebih tinggi, energinya membesar. Berdasarkan inilah, Tokeshi et al. (2008) mengestimasi frekuensi natural dengan menggunakan dispersi gelombang Rayleigh.

Nakamura (2008) menunjukkan efek gelombang Rayleigh terhadap kurva HVSR, kurva HVSR pada sekitar frekuensi natural tidak terpengaruh gelombang Rayleigh, namun frekuensi yang lebih tinggi terpengaruh. Pengaruh gelombang Rayleigh ini nampak pada puncak kedua HVSR. HVSR dengan tanpa pengaruh gelombang permukaan memiliki puncak kedua, sedangkan HVSR dengan pengaruh gelombang Rayleigh dengan besaran tertentu dapat menghilangkan puncak kedua pada HVSR. 


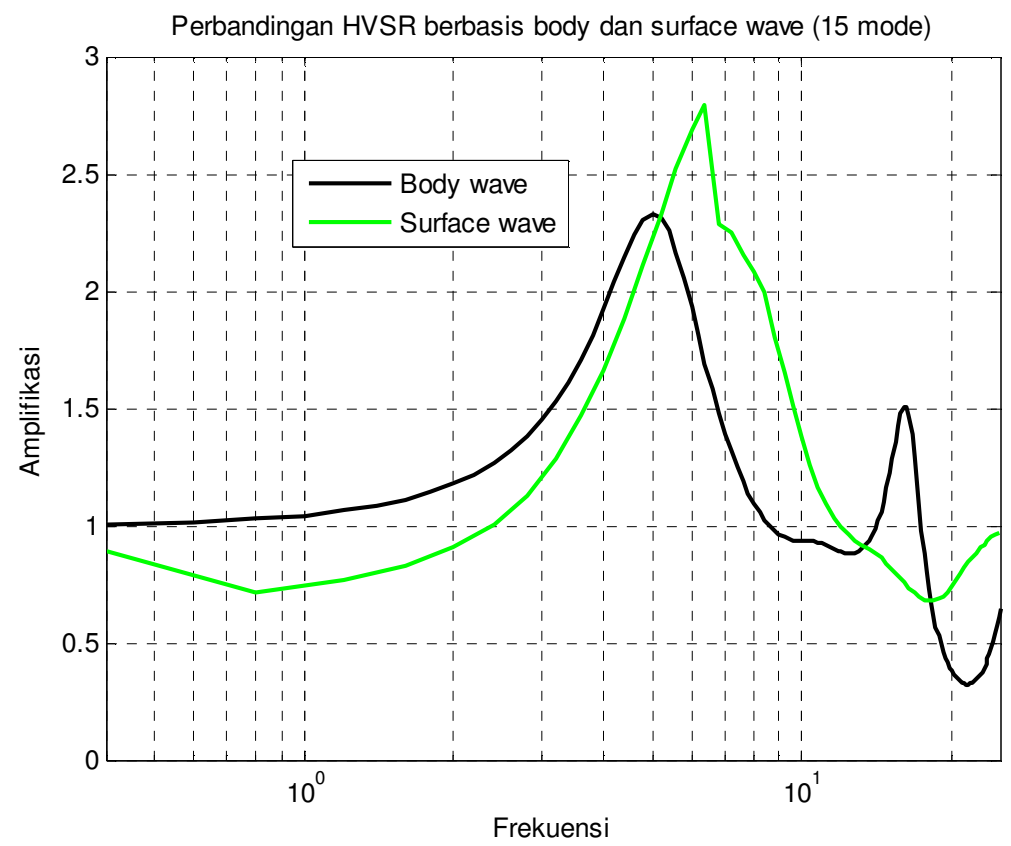

Gambar 2. Perbandingan HVSR berbasis gelombang badan dan multimode gelombang permukaan (15 mode)

\section{Karakteristik HVSR}

Setelah jelas bahwa kurva HVSR merupakan spektrum gelombang badan, tepatnya gelombang SH, maka permodelan ke depan untuk karakterisasi kurva HVSR dilakukan dengan menggunakan salah satu fungsi Software ModelHVSR yang dikembangkan oleh Herak (2008). ModelHVSR ini didasarkan pada medium homogen viscoelastisitas dengan gelombang vertikalnya diganti gelombang primer (secara teori gelombang SV), namun demikian, Herak (2008) menyatakan bahwa pendekatan ini valid. Menurut Herak (2008), terdapat enam parameter yang mempengaruhi kurva HVSR, antara lain:Vp, Vs, h, $\rho$, Qp dan Qs. Untuk mengetahui tingkat pengaruh keenam parameter tersebut, dapat dilakukan dengan melakukan cara permodelan ke depan yang memvariasikan satu variabel dengan variabel yang lainnya tetap. Karakterisasi ini, berguna untuk desain inversi kurva HVSR.

\subsection{Variasi ketebalan lapisan}

Efek variasi ketebalan lapisan terhadap kurva HVSR dapat diketahui dengan cara memodelkan kurva HVSR dengan input menvariasikan ketebalan lapisan dan parameter yang lainnya konstan (tabel 3). Hasil permodelan ini, nampak pada gambar 3. Berdasarkan gambar ini, diketahui bahwa ketebalan lapisan, yang berefek pada kedalaman bedrock, berpengaruh pada perbedaan frekuensi puncak kurva HVSR (frekuensi natural). Dan puncak kurva HVSR juga berbeda, walaupun perbedaannya relatif kecil. Ini mengidentifikasikan bahwa, ketebalan lapisan berpengaruh pada frekuensi natural dan nilai amplifikasi. Selain itu, kedalaman bedrock berbanding terbalik dengan frekuensi natural. Ini sesuai dengan persamaan yang didasarkan oleh Nakamura (2008), pers. (1). 
Tabel 3. Parameter permodelan HVSR pada variasi ketebalan lapisan

\begin{tabular}{|c|c|c|c|c|c|c|c|}
\hline \multirow{2}{*}{$\mathrm{Vp}(\mathrm{m} / \mathrm{s})$} & \multirow{2}{*}{$\mathrm{Vs}(\mathrm{m} / \mathrm{s})$} & \multirow{2}{*}{$\rho\left(\mathrm{gr} / \mathrm{cm}^{3}\right)$} & \multirow{2}{*}{ Qp } & Qs & \multicolumn{3}{|c|}{$\mathrm{H}(\mathrm{m})$} \\
\cline { 5 - 8 } & & & & & Model 1 & Model 2 & Model 3 \\
\hline 230 & 115 & 1.8 & 15 & 5 & 2 & 2 & 2 \\
\hline 750 & 250 & 1.8 & 30 & 10 & 10 & 20 & 50 \\
\hline 2100 & 915 & 1.9 & 150 & 50 & $\infty$ & $\infty$ & $\infty$ \\
\hline
\end{tabular}

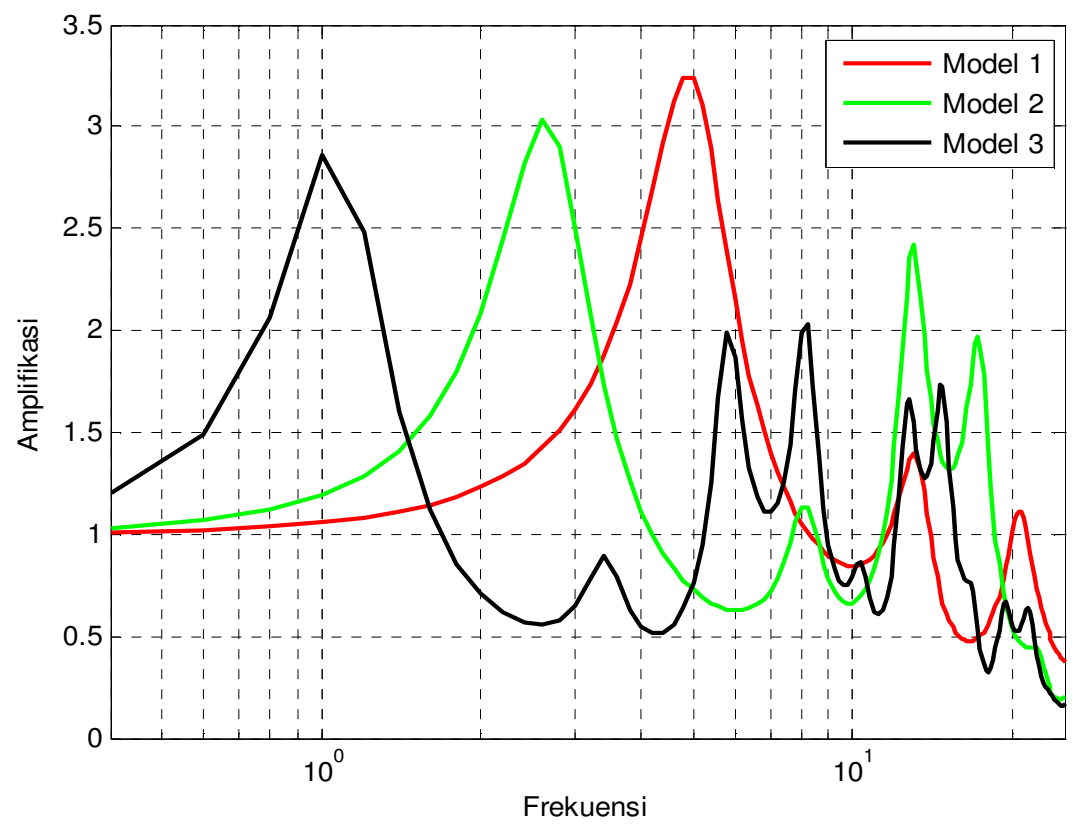

Gambar 3. Perbandingan HVSR model variasi ketebalan lapisan

\subsection{Variasi Kecepatan Gelombang Geser}

Dasar metode HVSR ialah terperangkapnya getaran gelombang SH pada medium sedimen di atas bedrock. Oleh karena itu, terdapat kemungkinan gelombang SH memberi peran yang sangat penting terhadap kurva HVSR. Untuk mengetahui tingkat pengaruh gelombang SH terhadap kurva HVSR, dilakukan permodelan ke depan dengan variasi kecepatan gelombang $S$, dengan parameter yang lainnya konstan (tabel 4). Hasil permodelan ke depan ini, nampak pada gambar 4. Hasil ini, memperlihatkan bahwa kecepatan gelombang geser sangat berpengaruh pada nilai frekuensi natural dan amplifikasi; berbeda dengan ketebalan lapisan yang hanya berpengaruh secara signifikan pada frekuensi natural. Amplifikasi model 1 yang paling tinggi, disusul amplifikasi model 2, dan yang terakhir ialah model 3. Ini karena kontras kecepatan bedrock dan lapisan diatasnya, secara berturut-turut dari tertinggi ke terendah ialah model 1, model 2 dan model 3. Selanjutnya, dilihat dari segi frekuensi natural, secara berturut-turut dari terendah ke tertinggi ialah model 1, model 2 dan model 3. Ini disebabkan oleh rata-rata kecepatan gelombang geser model $1<\operatorname{model} 2<\operatorname{model} 3$ (sesuai dengan pers. 1 ). 
Tabel 4. Parameter permodelan HVSR pada variasi kecepatan gelombang geser

\begin{tabular}{|c|c|c|c|c|c|c|c|}
\hline \multirow{2}{*}{$\mathrm{H}(\mathrm{m})$} & \multirow{2}{*}{$\mathrm{Vp}(\mathrm{m} / \mathrm{s})$} & \multirow{2}{*}{$\rho(\mathrm{gr} / \mathrm{cm} 3)$} & $\mathrm{Qp}$ & $\mathrm{2}$ & \multicolumn{3}{|c|}{$\mathrm{Qs}(\mathrm{m} / \mathrm{s})$} \\
\cline { 3 - 8 } & & & & & Model 1 & Model 2 & Model 3 \\
\hline 5 & 200 & 1.8 & 20 & 10 & 50 & 100 & 150 \\
\hline 4 & 600 & 1.8 & 45 & 30 & 200 & 300 & 400 \\
\hline 10 & 1200 & 1.9 & 45 & 30 & 300 & 400 & 500 \\
\hline 20 & 2000 & 2 & 45 & 30 & 700 & 800 & 900 \\
\hline & 3600 & 2.4 & & & 1600 & 1700 & 1800 \\
\hline
\end{tabular}

Parolai et al. (2002) dan Nath et al. (2009) membuat pendekatan frekuensi natural untuk mengestimasi kedalaman bedrock yang didasarkan pada data empiris di daerah Cologne Jerman untuk Parolai et al. (2002) (pers. 2a) dan Kota Guwahati untuk Nath dan Thingbaijan (2009) (pers. 2b). Kedua persamaan ini, menghasilkan kedalaman bedrock yang identik (Nath dan Thingbaijan, 2009). Kemungkinan kedua persamaan ini hanya berlaku pada masing-masing daerah tertentu saja. Sebab, frekuensi natural tidak hanya dipengaruhi oleh kedalaman bedrock saja, tetapi juga dipengaruhi rata-rata kecepatan bawah permukaan; berdasarkan gambar 4. Oleh karena itu, estimasi kedalaman bedrock yang didasarkan pada nilai frekuensi HVSR sebenarnya tidak relevan.

$$
\begin{aligned}
& h=108 f^{-1.551} \\
& h=125 f^{-1.459}
\end{aligned}
$$

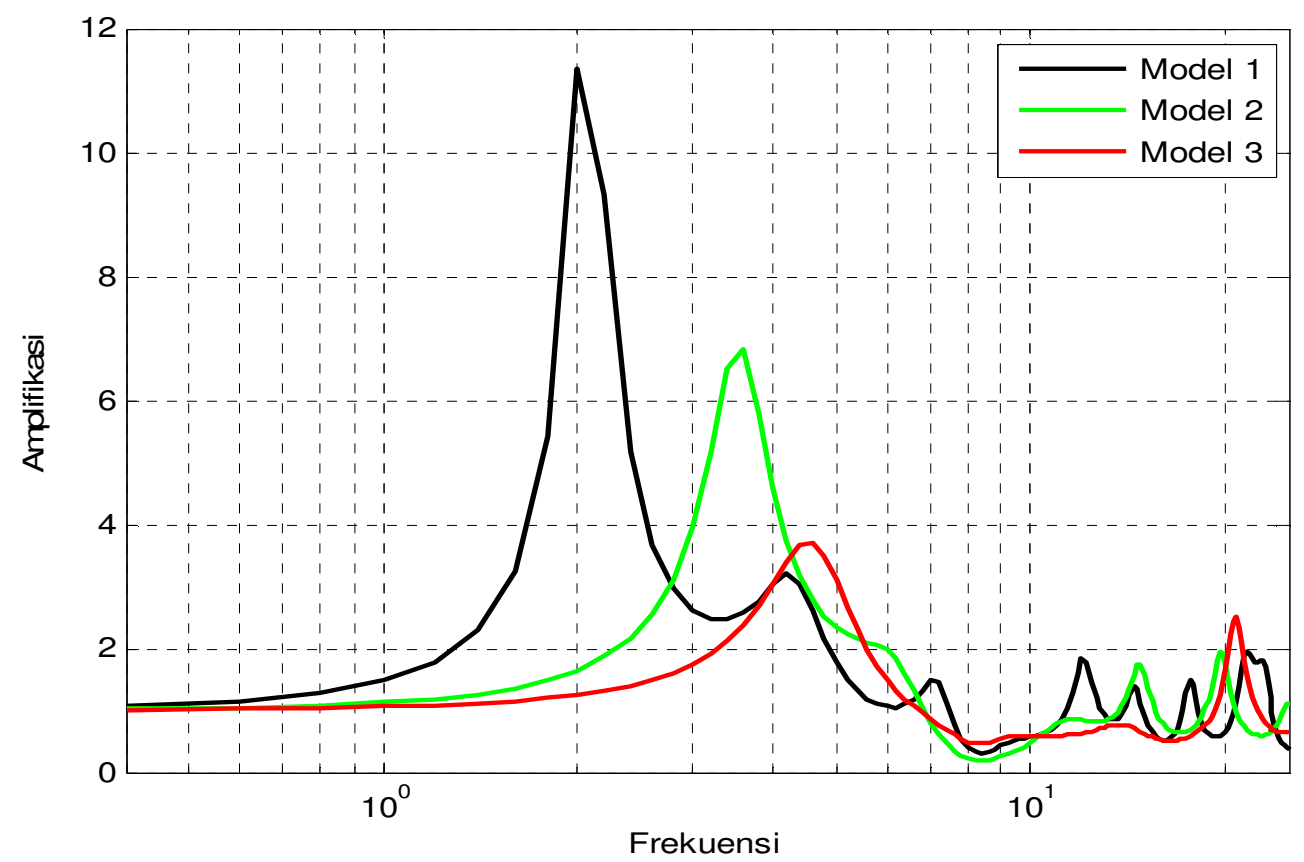

Gambar 4. Perbandingan HVSR model variasi kecepatan bawah permukaan Created with 


\subsection{Variasi Kecepatan Gelombang Primer lapisan}

Pengaruh kecepatan gelombang $\mathrm{P}(\mathrm{Vp})$ pada kurva HVSR didapatkan dari permodelan ke depan dengan input data memvariasikan kecepatan gelombang $\mathrm{P}$ dengan parameter lainnya konstan (tabel 5). Hasil permodelan ini sebagaimana gambar 5. Berdasarkan gambar ini, diketahui bahwa Vp tidak berpengaruh terhadap frekuensi natural dan berpengaruh terhadap amplifikasi. Yakni, amplifikasi berbanding lurus dengan Vp, namun pengaruh Vp pada kurva HVSR tidak sebesar Vs. Oleh karena itu, pada inversi kurva HVSR (Herak, 2008) maupun joint inversi kurva HVSR dengan kurva dispersi gelombang Rayleigh (Dal Moro, 2010c; Picozzi et al., 2009; Kuo, 2009) membuat Vp konstan, Vp diupdate dengan menggunakan hubungan Vs-rasio Poison dengan parameter rasio Poison yang konstan, $\mathrm{Vp}$ diupdate dengan menggunakan konstanta yang dikalikan dengan Vs. Dengan Vs-nya berubah sebagai fungsi iterasi.

Tabel 5. Parameter permodelan HVSR pada variasi kecepatan gelombang primer

\begin{tabular}{|c|c|c|c|c|c|l|l|}
\hline \multirow{2}{*}{$\mathrm{H}(\mathrm{m})$} & \multirow{2}{*}{$\mathrm{Vs}(\mathrm{m} / \mathrm{s})$} & \multirow{2}{*}{$\rho(\mathrm{gr} / \mathrm{cm} 3)$} & \multirow{2}{*}{ Qp } & Qs & \multicolumn{3}{|c|}{$\mathrm{Vp}(\mathrm{m} / \mathrm{s})$} \\
\cline { 5 - 8 } & & & & & Model 1 & Model 2 & Model 3 \\
\hline 5 & 100 & 1.8 & 20 & 10 & 200 & 400 & 600 \\
\hline 4 & 300 & 1.8 & 45 & 30 & 600 & 800 & 1000 \\
\hline 10 & 400 & 1.9 & 45 & 30 & 1200 & 1400 & 1600 \\
\hline 20 & 800 & 2 & 45 & 30 & 2000 & 2200 & 2400 \\
\hline$\infty$ & 1700 & 2.4 & & & 3600 & 3800 & 4000 \\
\hline
\end{tabular}

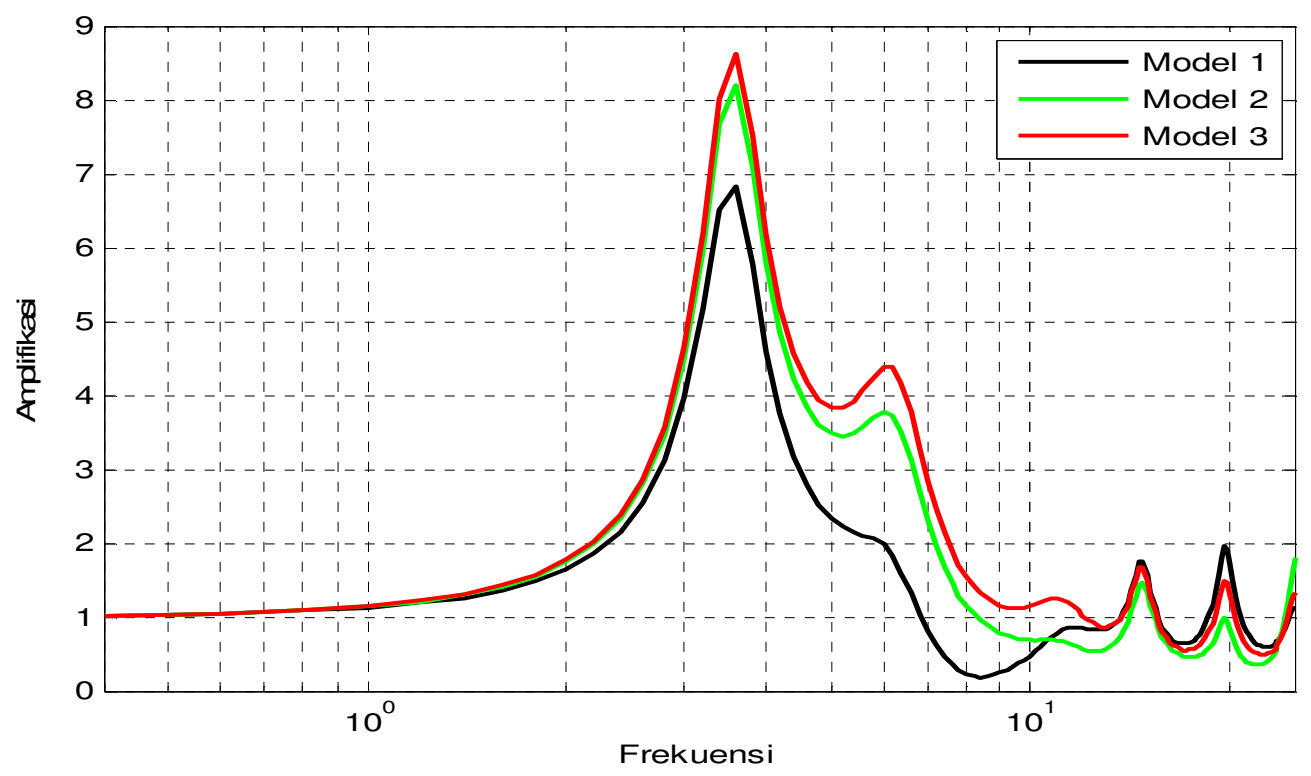

Gambar 5. Perbandingan HVSR model variasi kecepatan gelombang P lapisan 


\subsection{Variasi densitas lapisan}

Dal Moro (2010c) mengungkapkan bahwa kurva HVSR dipengaruhi oleh kontras impedansi. Artinya, kurva ini dipengaruhi oleh Vs dan densitas bawah permukaan. Untuk mengetahui tingkat pengaruh densitas terhadap kurva HVSR dilakukan permodelan ke depan dengan input variasi densitas dan parameter lainnya konstan (tabel 6). Hasil permodelan terlihat pada gambar 6. Gambar ini menunjukkan bahwa densitas mempengaruhi amplifikasi kurva HVSR dan tidak mempengaruhi frekuensi natural kurva HVSR. Dengan demikian, pengaruh densitas bawah permukaan pada kurva HVSR tidak sebesar Vs bawah permukaan.

Tabel 6. Parameter permodelan HVSR pada densitas

\begin{tabular}{|c|c|c|c|c|c|l|l|}
\hline \multirow{2}{*}{$\mathrm{H}(\mathrm{m})$} & \multirow{2}{*}{$\mathrm{Vs}(\mathrm{m} / \mathrm{s})$} & \multirow{2}{*}{$\mathrm{Vp}(\mathrm{m} / \mathrm{s})$} & \multirow{2}{*}{ Qp } & \multirow{2}{*}{ Qs } & \multicolumn{3}{|c|}{$\rho(\mathrm{cm} /$ gram3) } \\
\cline { 5 - 8 } & & & & & Model 1 & Model 2 & Model 3 \\
\hline 5 & 100 & 200 & 20 & 10 & 1.8 & 2.8 & 3.8 \\
\hline 4 & 300 & 600 & 45 & 30 & 1.8 & 2.8 & 3.8 \\
\hline 10 & 400 & 1200 & 45 & 30 & 1.9 & 2.9 & 3.9 \\
\hline 20 & 800 & 2000 & 45 & 30 & 2 & 3 & 4 \\
\hline$\infty$ & 1700 & 3600 & & & 2.4 & 3.4 & 4.4 \\
\hline
\end{tabular}

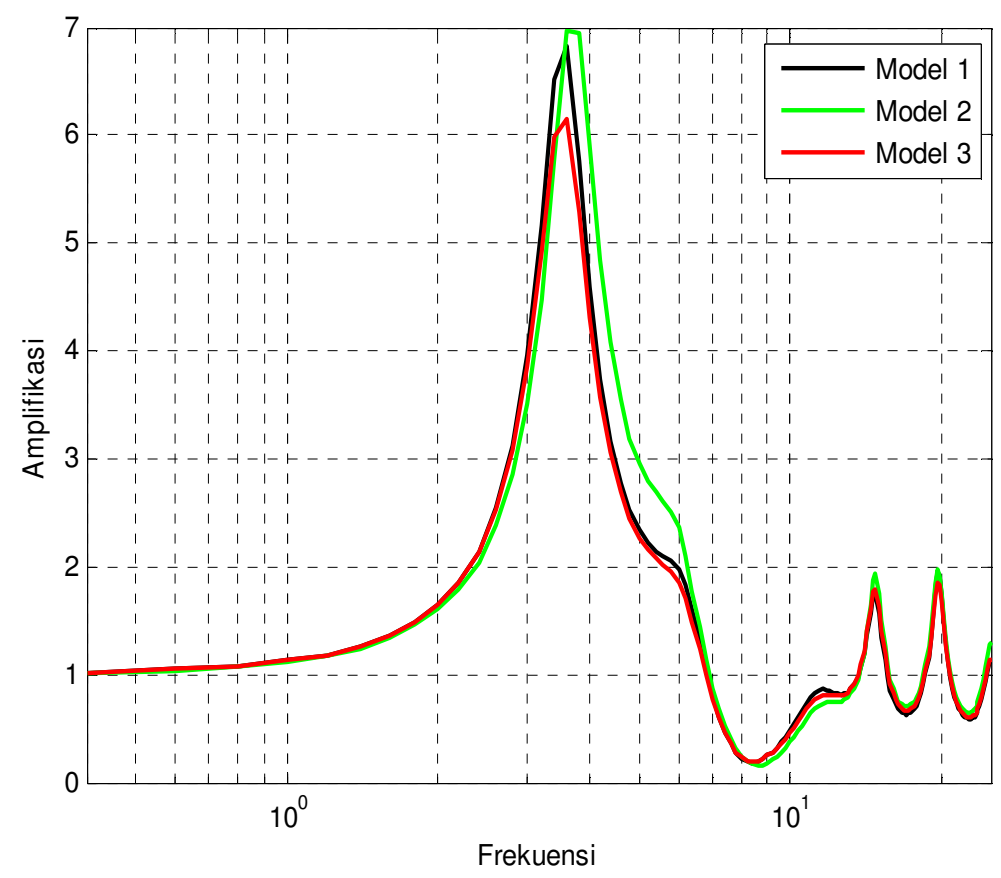

Gambar 6. Perbandingan HVSR model variasi densitas lapisan 


\subsection{Variasi faktor Quasi P}

Efek faktor quasi gelombang $\mathrm{P}(\mathrm{Qp})$ pada kurva HVSR diestimasi dengan menggunakan ModelHVSR (Herak, 2008) dengan cara memvariasikan parameter Qp dengan parameter lainnya tetap (tabel 7). Hasil permodelan ini didapatkan bahwa Qp tidak berpengaruh terhadap kurva HVSR (gambar 7) pada Vs/Vp rendah (rasio Poison tinggi), parameter ini pada umumnya terdapat pada batuan sedimen. Hal ini sesuai dengan Xia et al. (2002), yang mengatakan bahwa pada rasio Vs/Vp rendah, Qp memiliki efek kecil terhadap redaman gelombang.

Tabel 7. Parameter permodelan HVSR pada variasi faktor quasi gelombang primer (Qp)

\begin{tabular}{|c|c|c|c|c|c|c|l|}
\hline \multirow{2}{*}{$\mathrm{H}(\mathrm{m})$} & \multirow{2}{*}{$\mathrm{Vs}(\mathrm{m} / \mathrm{s})$} & $\mathrm{Vp}(\mathrm{m} / \mathrm{s})$ & \multirow{2}{*}{$\rho(\mathrm{gr} / \mathrm{cm} 3)$} & Qs & \multicolumn{3}{|c|}{ Qp } \\
\cline { 4 - 8 } & & & & & Model 1 & Model 2 & Model 3 \\
\hline 5 & 100 & 200 & 1.8 & 10 & 20 & 30 & 40 \\
\hline 4 & 300 & 600 & 1.8 & 30 & 45 & 60 & 70 \\
\hline 10 & 400 & 1200 & 1.9 & 30 & 45 & 60 & 70 \\
\hline 20 & 800 & 2000 & 2 & 30 & 45 & 60 & 70 \\
\hline & 1700 & 3600 & 2.4 & & & & \\
\hline
\end{tabular}

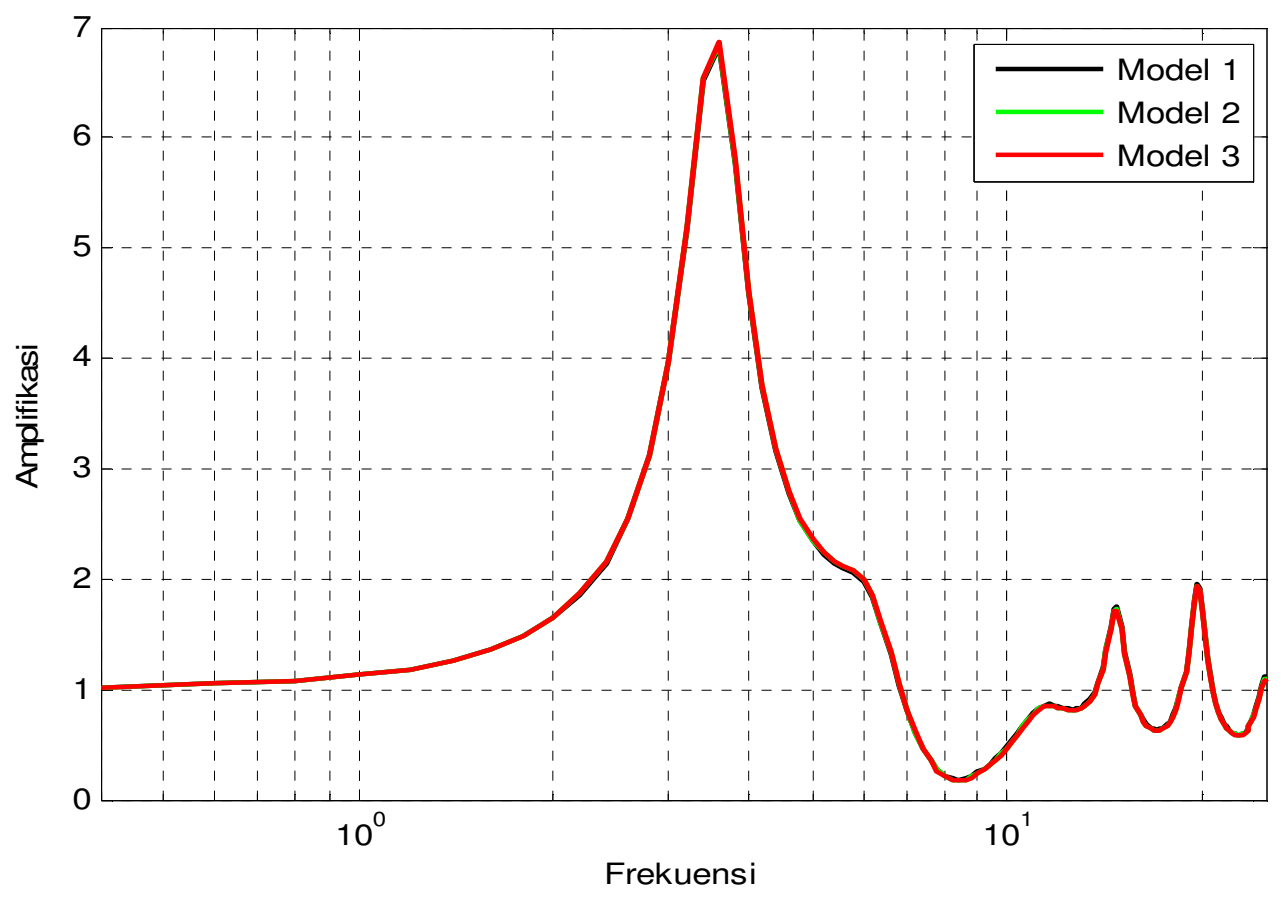

Gambar 7. Perbandingan HVSR model variasi Qp pada tiap lapisan 


\subsection{Variasi faktor Quasi S}

Variasi faktor quasi gelombang S (Qs) dengan parameter lain kontan diperlukan untuk karakterisasi kurva HVSR akibat parameter Qs. Hasil variasi parameter Qs ini nampak pada gambar 8. Gambar ini menunjukkan bahwa Qs berpengaruh terhadap amplifikasi kurva HVSR dan tidak berbengaruh terhadap frekuensi natural. Kuo (2009) menunjukkan bahwa penjalaran gelombang SH sebagai fungsi frekuensi (fungsi transfer gelombang $\mathrm{SH}$ ) dipengaruhi oleh faktor quasi gelombang geser (Qs). Amplitudo fungsi transfer gelombang SH berbanding lurus dengan Qs dan frekuensi amplitudo puncak tidak terpengaruh dengan Qs. Oleh karena itulah, amplifikasi tergantung Qs dan frekuensi natural tidak bergantung Qs. Hasil ini memperkuat hasil penelitian Meng (2007).

Tabel 8. Parameter permodelan HVSR pada variasi faktor quasi gelombang geser (Qs)

\begin{tabular}{|c|c|c|c|c|c|c|c|}
\hline \multirow{2}{*}{$\mathrm{H}(\mathrm{m})$} & \multirow{2}{*}{$\mathrm{Vs}(\mathrm{m} / \mathrm{s})$} & \multirow{2}{*}{$\mathrm{Vp}(\mathrm{m} / \mathrm{s})$} & \multirow{2}{*}{$\rho(\mathrm{gr} / \mathrm{cm} 3)$} & \multirow{2}{*}{ Qp } & \multicolumn{3}{|c|}{ Qs } \\
\hline & & & & & Model 1 & Model 2 & Model 3 \\
\hline 5 & 100 & 200 & 1.8 & 20 & 5 & 10 & 15 \\
\hline 4 & 300 & 600 & 1.8 & 45 & 20 & 25 & 30 \\
\hline 10 & 400 & 1200 & 1.9 & 45 & 20 & 25 & 30 \\
\hline 20 & 800 & 2000 & 2 & 45 & 20 & 25 & 30 \\
\hline & 1700 & 3600 & 2.4 & & & & \\
\hline
\end{tabular}

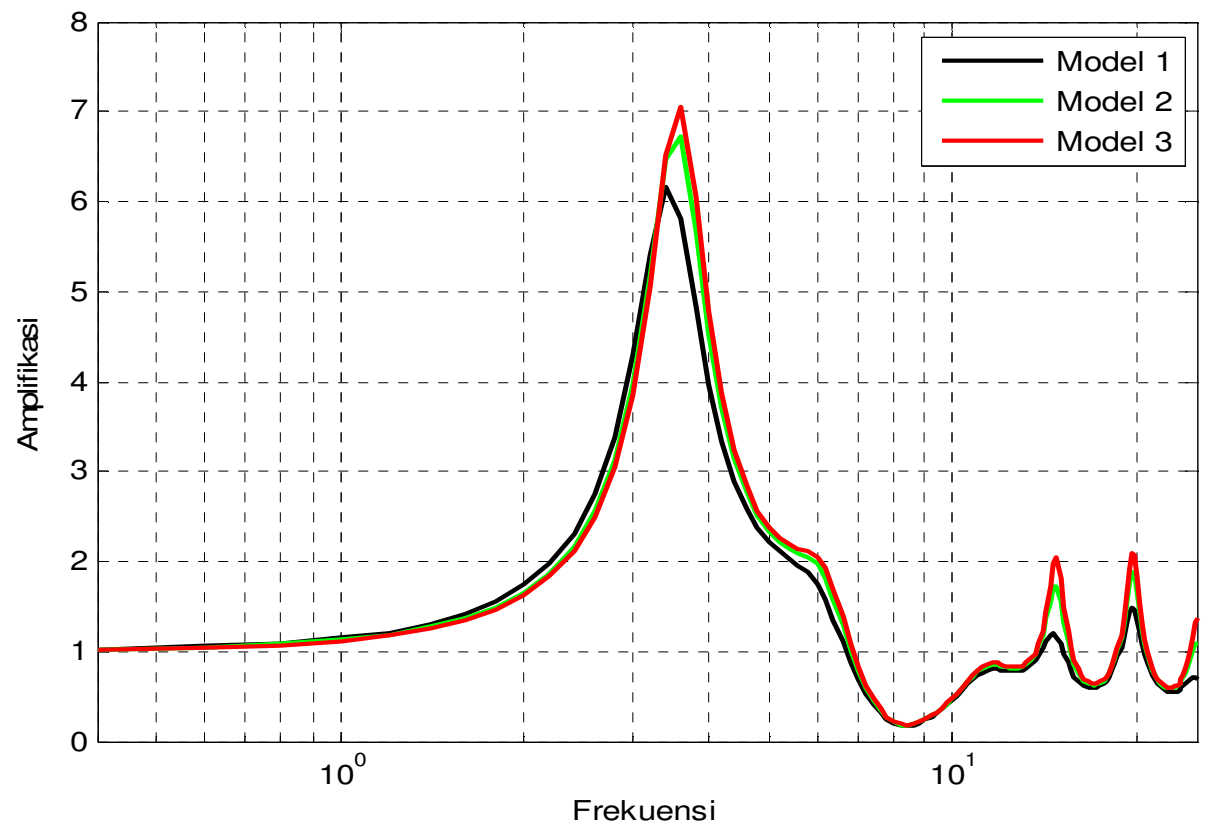

Gambar 8. Perbandingan HVSR model variasi faktor Qs setiap lapisan 


\section{Efek lokal HVSR dan Kerusakan akibat gempabumi}

Telah dilaporkan oleh beberapa peneliti (Nakamura et al.,2000, Herak et al., 2009; Daryono dkk., 2009; Hasancebi \& Ulusay, 2006), bahwa kerusakan bangunan akibat gempa dipengaruhi oleh efek lokal, yakni geologi setempat. Efek lokal yang dapat menyebab kerusakan akibat gempabumi berkorelasi dengan parameter HVSR microtremor, yang dicirikan oleh frekuensi natural rendah (periode tinggi) dan amplifikasi tinggi.

Frekuensi natural, merepresentasikan banyaknya gelombang yang terjadi dalam satuan waktu. Frekuensi natural dipengaruhi oleh besarnya kecepatan rata-rata dan ketebalan sedimen bawah permukaan. Berdasarkan pers. (1), frekuensi natural berbanding terbalik dengan ketebalan sedimen (ketebalan bedrock) dan berbanding lurus dengan kecepatan rata-rata. Selanjutnya, dengan menghubungkan kerusakan bangunan akibat getaran gempabumi dengan kedua parameter tersebut, dapat diketahui bahwa daerah yang rawan kerusakan bangunan akibat getaran gempa terjadi pada dearah dengan geologi lapisan sedimen tebal dan atau lapisan permukaan berupa soft sedimen, contohnya:pasir, pasir lanauan, gambut. Hal ini sesuai dengan hasil penelitian yang dilakukan oleh Daryono dkk. (2009) yang menunjukkan bahwa, bangunan yang dibangun di dearah sedimentasi yang berasal dari lahar merapi dan sungai, tingkat kerusakannya lebih besar dari pada bangunan yang dibangun diperbukitan.

Sedangkan parameter amplifikasi HVSR, penggunaannya masih diperdebatkan. Ini disebabkan oleh dua hal. Pertama, nilai amplifikasi HVSR mikrotremor berbeda dengan amplifikasi HVSR seismogram (SESAME, 2004). Kedua, amplifikasi HVSR data mikrotremor dipengaruhi oleh sumber getaran (SESAME, 2004; Herak, 2008). Menurut Dal Moro (2010), perbedaan nilai amplifikasi mikrotremor dan seismogram, kemungkinan disebabkan oleh metode filtering, sifat statistik smoothing, dan rata-rata pada HVSR yang tidak robust. Oleh karena itu, Herak et. al. (2009) dalam mikrozonasi bahaya kerusakan bangunan, tidak menggunakan amplifikasi HVSR mikrotremor secara langsung, tetapi menggunakan amplifikasi HVSR yang telah terkoreksi dengan besarnya sumbergempa disekitar wilayah yang di estimasi mikrozonasinya. Sedangkan Nakamura et al. (2000), hanya menggunakan amplifikasi HVSR mikrotremor yang datanya stasioner, sedangkan data mikrotremor yang transien amplifikasinya tidak digunakan, walaupun frekuensinya digunakan.

Amplifikasi kurva HVSR dipengaruhi oleh VS, densitas, Vp, dan Qs. Tepatnya, berbanding lurus dengan kontras impedansi (Vs*densitas) antara sedimen dan bedrock, berbanding lurus dengan Vp dan Qs. Dengan demikian, dapat diketahui bahwa daerah yang rawan kerusakan bangunan akibat getaran gempa ialah, daerah yang permukaannya tersusun atas sedimen lunak (gambut, pasir, pasir lanauan) dengan bedrock yang keras. Karena pada geologi yang seperti ini, kontras (perbedaan antara lapisan sedimen dan bedrock) impedansinya besar.

Data amplifikasi dan frekuensi natural hasil HVSR, tidak berkorelasi. Dengan demikian, microzonasi dengan mempertimbangkan keduanya agak rumit. Untuk itu, 
diperkenalkan parameter lain, dalam hal ini indeks kerentanan tanah (pers. 3). Menurut (Nakamura, 1998; Huang dan Tseng, 2002) bahwa Indeks kerentanan tanah (Kg) mengidentifikasikan likuifaksi akibat gempabumi.

$$
K_{g}=\frac{A_{\mathrm{m}}}{f}
$$

Dengan $A m$ dan $f$ ialah amplifikasi dan frekuensi HVSR.

Indeks kerentanan telah diaplikasikan oleh Daryono dkk. (2009), Nakamura et al. (2000) dan Huang dan Tseng (2002) yang menunjukkan bahwa kerusakan bangunan berbanding lurus dengan tingkat kerusakan bangunan. Dengan demikian, untuk melakukan zonasi tingkat kerusakan bangunan akibat gempabumi, dapat dilakukan dengan pengukuran dan analisa mikrotremor dengan mengaplikasikan pers. (3). Namun, kendala terjadi jika pengukuran data mikrotremor terpengaruh noise, sehingga data mikrotremor berupa data transient dan amplifikasi HVSR data mikrotremor tidak valid. Efeknya zonasi dengan metode 3 tidak dapat dilakukan. Sedangkan frekuensi naturalnya seringkali tetap valid (SESAME, 2004). Pada kondisi seperti ini, microzonasi dengan parameter hasil HVSR, dapat dilakukan dengan menggunakan clustering berbasis Fuzzy imputasi, sebagaimana yang sedang penulis kerjakan saat ini (hasilnya belum fix).

\section{KESIMPULAN}

Parameter HVSR (amplifikasi dan frekuensi natural) dapat digunakan untuk mikrozonasi kerusakan bangunan akibat getaran gempabumi. Untuk mengetahui karakter struktur bawah permukaan yang dapat menyebabkan kerusakan bangunan dan karakter kurva HVSR, dilakukan perbandingan pemodelan HVSR berbasis gelombang badan dan gelombang permukaan dan karakterisasi kurva HVSR. Hasilnya pemodelan didapatkan bahwa kurva HVSR merupakan gabungan antara gelombang badan dan gelombang permukaan. Pada daerah frekuensi natural, HVSR lebih mendekati gelombang badan, sedangkan untuk frekuensi yang lebih tinggi, gelombang badan dipengaruhi gelombang permukaan. Dengan demikian, HVSR lebih dekat dengan gelombang badan dari pada gelombang permukaan.

Karakterisasi HVSR yang dilakukan dengan dasar gelombang badan diketahui bahwa frekuensi natural tergantung Vs dan ketebalan sedimen bawah permukaan. Amplifikasi berbanding lurus dengan kontras impedansi, Vp dan Qs. Selanjutnya, dapat diketahui bahwa kerusakan bangunan akibat gempa terjadi pada sedimen lapuk yang tebal dan atau sedimen lapuk yang terdapat diatas batuan yang keras.

\section{DAFTAR PUSTAKA}

Albarello, D., and Lunedei, E.(2010). Alternative interpretations of horizontal to vertical spectral ratios of ambient vibrations: new insights from theoretical modeling. Bulletin of Earthquake Engineering 8, 519-534. 
Ali, MY., Berteussen, KA., Small, J., Barka,B. (2010). Low-frequency passive seismic experiments in Abu Dhabi, United Arab Emirates: implications for hydrocarbon detection. Geophysical Prospecting. doi: 10.1111/j.1365-2478.2009.00835.x

Arai, H., and Tokimatsu, K. (2000). Effects of Rayleigh and love waves on microtremor $\mathrm{H} / \mathrm{V}$ spectra. $12 \mathrm{WCEE}$

Arai, H., and Tokimatsu, K.(2005). S-wave velocity profiling by joint inversion of microtremor dispersion curve and horizontal-to-vertical (H/V) spectrum. BSA, Vol. 95, No. 5, pp.1766-1778, October 2005, doi:10.1785/0120040243.

Bonnefoy-Claudet,S., Cornou,C.,Bard,PY., Cotton,F., Moczo,P., Kristek, J., and Fäh, D.(2006a). H/V ratio: a tool for site effects evaluation. Results from 1-D noise simulation.Geophys Journal Int.Vol.167,pp.827-837.

Bonnefoy-Claudet, S, Cotton, F., Bard, P.Y.(2006b). The nature of noise wavefield and its applications for site effects studies, Earth-Science Reviews. doi:10.1016/j.earscirev.2006.07.004

Dal Moro, G.(2010). Some Thorny Aspects about Surface Wave and HVSR Analyses: an Overview. Bollettino di Geofisica Teorica e Applicata, special issue, submitted.

Gallipolia,M.R., M. Mucciarellia, R.R. Castroc, G. Monachesid, P. Contrie. (2004).Structure, soil-structure response and effects of damage based on observations of horizontal-to-vertical spectral ratios of microtremors. Soil Dynamics and Earthquake Engineering, Vol.24, pp:487-495

Herak, M. (2008). ModelHVSR: a Matlab tool to model horizontal-to-vertical spectral ratio of ambient noise. Computers and Geosciences 34, 1514-1526.

Huang, H.C., Tseng, Y.S. (2002). Characteristics of soil liquefaction using H/V of microtremorsin Yuan-Lin Area, Taiwan. TAO, Vol. 13, No. 3, 325-338, September 2002.

Konno, K., and Ohmachi, T. (1998). Ground-Motion Characteristics Estimated from Spectral Ratio between Horizontal and Vertical Components of Microtremor. Bulletin of the Seismological Society of America, vol. 88, No. 1, pp 228-241.

Lunedei, E., \& Albarello, D.(2009). On the seismic noise wavefield in a weakly dissipative layered Earth. Geophysical Journal International 177, 1001-1014.

Meng, J. (2007). Earthquake ground motion simulation with frequency-dependent soil properties. Soil Dynamics and Earthquake Engineering Vol. 27.pp.234-241

Mucciarelli, M., A. Masi, M. R. Gallipoli, P. Harabaglia, M. Vona, F. Ponzo, and M. Dolce. (2004).Analysis of RC Building Dynamic Response and Soil-Building Resonance Based on Data Recorded during a Damaging Earthquake (Molise, Italy, 2002). Bulletin of the Seismological Society of America, Vol. 94, No. 5, pp. 1943-1953, October 2004

Nakamura, Y. (1989). A method for dynamic characteristics estimation of subsurface using microtremor on the ground surface. Quarterly Report of Railway Technical Research Inst. (RTRI) 30, 25-33.

Nakamura, Y. (1996). Realtime Information Systems for Seismic Hazard Mitigation. Quarterly report of Railway Technical Research Inst. (RTRI) 37, 112-127.

Nakamura, Y. (1997). Seismic Vulnerability Indices For Ground And Structures Using Microtremor. World Congress on Railway Research, Florence, Nov. 
Nakamura, Y. (2000). Clear identification of fundamental idea of Nakamura's technique and its applications. Proc XII World Conf. Earthquake Engineering, New Zealand,2656.

Nakamura, Y., E.D. Gurler, J. Saita, A. Rovelli, S. Donati . (2000). Vulnerability Investigation Of Roman Colosseum Using Microtremor. Prepared for 12th WCEE 2000 in Auckland, NZ

Nakamura, Y. (2008). On The H/V Spectrum. The $14^{\text {th }}$ World Conference on Earthquake Engineering October 12-17, 2008, Beijing, China

Panoua, A.A., N. Theodulidis, P. Hatzidimitriou, K. Stylianidis, C.B. Papazachos. (2005). Ambient noise horizontal-to-vertical spectral ratio in site effects estimation and correlation with seismic damage distribution in urban environment: the case of the city of Thessaloniki (Northern Greece). Soil Dynamics and Earthquake Engineering, Vol.25,pp: 261-274

Parolai, S., Bormann, P., Milkereit, C.,(2002). New relationships between Vs, thickness of the sediments and resonance frequency calculated by means of H/V ratio of seismic noise for the Cologne area (Germany). Bull. Seismol. Soc. Am. 92 (6), 2521- 2527.

Rosenblad, BL, Goetz, R. (2010).Study of the H/V spectral ratio method for determining average shear wave velocities in the Mississippi embayment.

Sato, T., Y. Nakamura, J. Saita. The Change Of The Dynamic Characteristics Using Microtremor. The 14 th World Conference on Earthquake Engineering October 12-17, 2008, Beijing, China

SESAME. (2004). Site Effects Assessment Using Ambient Excitations. European Commission - Research General Directorate Project No. EVG1-CT-2000-00026 SESAME. Report of the WP04 H/V Technique : Empirical Evaluation.

Tokeshi, K., Karkee, M., and Cuadra, C. (2008). Estimation of vs profile using its natural frequency and Rayleigh-wave dispersion characteristics. Adv. Geosci., 14, 7577, 2008

Triwulan, Utama, W., Warnana, D.D., Sungkono. 2011.Soil-Structure Resonance Base On Observations Of Horisontal-to-Vertical Spectral Ratios Of Microtremor (Case Study: Pare, Kediri District-East Java). Submitted to The Second International Conference on Earthquake Engineering and Disaster Mitigation (ICEEDM-2). 19-20 July Surabaya, Indonesia.

Triwulan, Utama, W., Warnana, D.D., Sungkono. Vulnerability index estimation for building and ground using microtremor. Aptecs $2^{\text {nd }}$. International Seminar on applied Technology, Science and Arts. Graha Sepuluh Nopember, Institut Teknologi Sepuluh Nopember Surabaya. 21-22 Desember 2010 